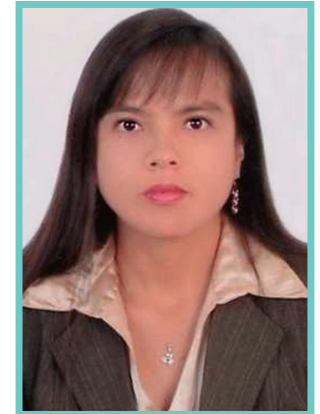

Victoria Higa

Cisneros

\title{
¿EL DOCENTE DEBE TENER ESTRATEGIAS CREATIVAS EN LA ENSEÑANZA UNIVERSITARIA?
}

\section{RESUMEN}

Artículo que asocia la buena educación a la creatividad. Quien es buen maestro, debe ser creativo para, a su vez, ayudar a que sus estudiantes accedan a aprendizajes de la misma índole.

PALABRAS CLAVE

Educación, enseñanza, creatividad, aprendizaje creativo.

\section{ABSTRACT}

This article associates good education to creativity. Who is a good teacher should be creative, in order to help their students to access learning of the same nature.

KEYWORDS

Education, creativity, creative learning.
T Tna profesora muy querida me invitó a escribir un artículo para esta revista. Al principio tuve mis dudas en cómo podría colaborar con ella, pues era la primera vez que lo hacía para el ámbito educativo, pero bueno, me eché los temores a la espalda y heme aquí intentando escribir un artículo con sentido para ustedes estimados lectores, donde abordaré algunas estrategias didácticas que el docente puede emplear, pues es muy importante que quien enseña sea innovador y creativo para poder desarrollar en el alumno habilidades de pensamiento y actitudes sin dejar de lado los conocimientos.

No cabe duda que hoy en día, en esta sociedad del conocimiento, la enseñanza universitaria está en un momento de transformación y búsqueda apremiado por la realidad social y la demanda de calidad. 
La educación en general está tratando de ser un espacio más abierto y flexible que prepare personas y profesionales para enfrentar la vida, que busque soluciones a los problemas que tiene la sociedad actual. Este proceso de transformación a través de la educación debe empezar, por tanto, por la creatividad.

Mucho se hace énfasis en la metodología como herramienta fundamental para llevar a cabo el cambio de los tradicionales contenidos académicos a contenidos profesionales centrados en el desarrollo de habilidades y competencias centradas en el alumno.

La creatividad, es la esencia de las estrategias innovadoras orientadas al aprendizaje, pues es el alumno el que va adquiriendo las competencias necesarias en cada una de las carreras profesionales.

Según la RAE (Real Academia Española), un profesional es una persona competente que ejerce su profesión con relevante capacidad y aplicación, capaz de analizar y resolver los problemas y proponer mejoras (innovar). El docente universitario es un profesional de la enseñanza superior, con dominio del contenido formativo y de estrategias didácticas, capaz de hacer que los alumnos se entusiasmen por aprender.

Esto pudiera ser la clave para plantear la labor docente en las universidades. Los docentes pueden elaborar y aplicar en sus sesiones de clases, distintas estrategias de carácter innovador y creativo, que se caractericen por ser estrategias orientadas al desarrollo de actitudes, valores, sensibilidad emocional y de persistencia en la labor iniciada, buscando potenciar las capacidades y habilidades de ideación, interacción, elaboración, competencia comunicativa y argumentativa para expresar y defender los propios puntos de vista, trabajo colaborativo, desempeño de roles, entre otros.

En las estrategias creativas, que se caracterizan por ser activa, motivadora, dinámica, implicativa, el alumno es el protagonista de su propio aprendizaje porque va construyendo los conocimientos y desarrollando habilidades guiadas por el docente, lo que resulta un aprendizaje más interesante y motivador, pues el alumno no solo se limita a registrar la información recibida, sino que al ser conocimiento de carácter colaborativo o compartido del conocimiento, el alumno se enriquece comparando información en grupo.

"El aprendizaje creativo hace referencia al conocimiento construido con la implicación activa del sujeto, desde su planificación hasta su internalización, caracterizado por la motivación intrínseca, estar centrado en el discente, carácter abierto del proceso y la autoevaluación" (S. de la Torre, 1993. p. 272).

No hay una receta estandarizada que enseñe a resolver los problemas de desmotivación en los alumnos; sin embargo, la clave está en el docente, que tiene la habilidad para diseñar estrategias que afronten dichas situaciones.

Muchos docentes terminan su formación dominandolos contenidosquevanimpartir, pero es a través de la práctica que van adquiriendo las habilidades necesarias para actuar como buenos docentes; sin embargo, lo que no aprenden durante su formación profesional ni adquieren a través de la práctica son las competencias que les conviertan en "profesionales de la enseñanza innovadores y creativos", frase que define mejor al docente de hoy. Por tanto, el docente de hoy es más que un mero transmisor y evaluador de conocimientos, pues además de organizar las actividades académicas con más variedad de estrategias y recursos didácticos, debe adecuar los objetivos y necesidades al grupo de clase.

Un profesional de la enseñanza debe tener competencias no solo para resolver problemas o situaciones concretas, sino que debe conocer el porqué y para qué de aquello en lo que se ocupa; debe ser una persona reflexiva, capaz de analizar y mejorar su práctica; tener una visión capaz de ir más allá del problema o situación, conectar la teoría, la técnica y la práctica. Es por ello que el docente ha de tener unas competencias respecto al contenido y a la didáctica para 
involucrar al alumno en su dominio, además debe ser capaz de actualizarse y desarrollarse profesionalmente.

La creatividad y la innovación no solo deben ser una capacidad sino también una habilidad y actitud ante las personas y los hechos; el docente innovador y creativo debe tener unas características presentes en educación: ser, saber y hacer; es decir, tener actitudes flexibles, dominio de los contenidos y habilidad didáctica.

Así también, debe tener una disposición flexible hacia las personas, las decisiones y los sucesos; no solo tolerar los cambios sino que esté abierto a ellos más que otras personas; ser receptivo a ideas y sugerencias de los otros, ya sean superiores, compañeros o inferiores; adaptarse fácilmente a lo nuevo e implicarse en proyectos de innovación.

El docente innovador y creativo de la enseñanza, debe tener la habilidad para entusiasmar e inducir a los alumnos hacia el autoaprendizaje, hacerles interesante el contenido, que disfruten aprendiendo haciendo aportaciones personales, que creen o recreen los aprendizajes, porque la creatividad docente radica en dejar huella, de tal manera que pasado el tiempo se recuerde a aquellos profesores que les trasmitieron algo más que solo información.

Entonces todo esto debe ir de la mano con la estrategia didáctica que debe tener el docente.

La estrategia, entendida como procedimiento adaptativo o conjunto de ellos por el que se organiza secuenciadamente la acción para lograr el propósito o meta deseado, es un concepto amplio, abierto, flexible, interactivo y sobre todo adaptativo, aplicable tanto a la concreción de modelos de formación, de investigación, de innovación educativa, de evaluación, docencia o estimulación de la creatividad.

Las estrategias creativas pueden ser tantas como pueda imaginar el docente, pero el secreto del éxito está en captar y entusiasmar al alumno en aquellos aprendizajes que sean capaces de conectar con la vida diaria o con las inquietudes personales. Porque ¿Quién, mínimamente curioso, puede desentenderse de aquellos aprendizajes que uno puede aplicar a la vida? Lo expresó Albert Einstein con estas palabras: "El arte más importante del maestro es despertar en sus educandos la alegría de crear y de conocer".

Para concluir este artículo, quiero compartir con ustedes la reflexión que hace un alumno el último día de clase, en forma de carta a la creatividad, donde evidencia ese aprendizaje logrado con trabajo, entusiasmo y satisfacción; sobre todo con un alto grado de satisfacción y lo que es más insólito, tristeza porque acaben las clases. ¿Qué docente ha escuchado alguna vez a los alumnos decir que se sienten tristes por acabar las clases? Eso es posible si se han utilizado estrategias creativas.

"Amiga creatividad: llegó el momento de la despedida y no sé cómo se sentirán los demás, pero yo ya siento el gusanito de la tristeza que empieza a crecer en mi pecho.

Recuerdo cómo empezó todo un cálido día de septiembre, cuando te conocimos; o mejor debería decir, cuando fuimos conscientes de que estabas ahí. El profesor te presentó y al principio fue difícil reconocerte; pero poco a poco te hemos ido redescubriendo en nosotros y con cada actividad que hacíamos te íbamos conociendo mejor. Ahora no te digo adiós, sino hasta pronto, porque vas a estar en mi corazón -y estoy segura que en el de mis compañeros- por siemprey para siempre. Saldrás de nosotros en cada susurro, en cada beso, en cada poema que dediquemos a aquellos a quienes amamos, pues el amor puede ser el más bello acto creativo. También estás en nosotros cada vez que inducimos una sonrisa y cuando aceptamos con humor los contratiempos. Sé que estarás con nosotros cada vez que un amigo entra en nuestra vida, porque tú le abrirás la puerta.

Creatividad amiga, te presentaron como crea-en-tivida, pero yo te conocí en ti misma y me has deslumbrado. Sé que formas parte de mí y yo de ti, sé que has dejado huella en mí y ahora yo sé cómo dejar huella en los demás. Por eso, gracias, maestro." (A.S.S) 


\section{REFERENCIAS}

De Vicente. P. (Dir). (2002). Desarrollo profesional del docente. Bilbao: ICE Deusto.

Einstein, A. (1987). Cómo veo el mundo. Buenos Aires: Siglo XX.
Torre, S. de la y Barrios O. (2000) (Eds). Estrategias didácticas innovadoras y creativas. Barcelona: Octaedro. pp. 108-128. 